\title{
Evaluation of the concurrent use of lidocaine and ketamine infusions as adjunctive analgesia in the intensive care unit
}

\author{
Alex EBIED 1 (D), Abigail ANTIGUA $2 *$ \\ 1 Department of Pharmacotherapy and Translational Research, University of Florida, College of Pharmacy, \\ Gainesville, FL, United States of America \\ 2 Cardiovascular Surgery and Medicine, North Florida Regional Medical Center, Gainesville, FL, United States of \\ America \\ * Corresponding Author. E-mail: abigail55@gmail.com (A.A.); Tel. + 352-333-41 70.
}

Received: 20 November 2018 / Revised: 15 February 2019 / Accepted: 20 February 2019

\begin{abstract}
The purpose of this study was to determine the safety and effectiveness of ketamine and lidocaine infusions for the management of pain in surgical critically ill patients. This is a retrospective case series with a total of seven patients aged 18 years or older, had ICU stay at least 24 hours, and received concurrent use of systemic lidocaine and ketamine infusions as an adjunct therapy for pain management were enrolled between March 2014 to August 2015. The primary outcomes included the time measurement to achieve a $20 \%$ reduction in pain scores after the initiation of lidocaine and ketamine and the difference in opioid requirements pre and post concurrent pain therapies. Secondary outcomes include development of adverse events while on dual therapy. The median time to achieve a $20 \%$ pain score reduction was 2 hours. The median opioid requirements was reduced comparing prior to the ketamine and lidocaine infusions and 24 hours while on dual therapy (morphine dose equivalent $90.33 \mathrm{mg}$ vs. $56 \mathrm{mg}$ ). Two neurological adverse events were noted. The results of this study suggest that low-dose lidocaine and ketamine infusions can be a safe and effective adjunctive treatment option for selected ICU patients with severe pain. However, future studies need to be conducted to determine the safety and effectiveness of concurrent use of lidocaine and ketamine infusions aside from surgical ICU patients.
\end{abstract}

KEYWORDS: Adverse drug reactions; analgesics; critical care; ketamine; lidocaine.

\section{INTRODUCTION}

Critically ill patients may have several sources of pain including underlying illness, procedures, interventions while in the intensive care unit (ICU), and others. The Society of Critical Care Medicine (SCCM) guidelines on pain, agitation, and delirium address goals for pain management including to provide optimal patient comfort [1]. The other goals for pain management are to be patient-specific and to limit the adverse effects related to analgesic therapy. There are two options for pain to be managed in the ICU: opioids or nonopioids. Additionally, there are various routes for medication administration such as continuous intravenous (IV) infusion, IV bolus, oral, or other (i.e., transdermal, intranasal, mucosal).

IV opioids are primarily used to resolve pain in the ICU due to its effectiveness and quick onset of action. However, there are several side effects that limit its use as well. Opioids depress the central nervous system (CNS) which can cause somnolence and hallucinations. Furthermore, respiratory depression can be observed leading to longer days of mechanical ventilation or re-intubations. Other side effects that can be observed include ileus, urinary retention, hypotension and pain tolerance which can further prolong ICU and hospital stay [2].

The SCCM guidelines promote the use of multimodal approach to attempt and limit the use of opioids [2]. Both lidocaine and ketamine infusions are non-opioid options for the treatment of pain. Lidocaine is a sodium channel blocking anesthetic with recent data to support its use as an adjunct analgesic agent for various types of pain, including pain from surgery or neuropathy [3-5]. Ketamine is a N-methyl-D-aspartate (NMDA) receptor antagonist to block nociceptive and inflammatory pain transmission [6].

Lidocaine and ketamine have promising roles in pain management in the ICU due to the fast onsets of action ( 7 to 30 minutes for lidocaine and 30 seconds for ketamine) and lack of respiratory depression. However,

How to cite this article: Ebied A, Antigua A. Evaluation of the concurrent use of lidocaine and ketamine infusions as adjunctive analgesia in the intensive care unit. J Res Pharm. 2019; 23(4): 617-620. 
the safety and effectiveness of concurrent use of both infusions as adjuncts for pain in the ICU setting have not been well studied [3-5] .

The purpose of this study was to determine the safety and effectiveness of ketamine and lidocaine infusions for the management of pain in surgical critically ill patients.

\section{RESULTS}

A total of seven adult surgical ICU patients received lidocaine and ketamine infusions concurrently and were initiated simultaneously. Patients were stratified to: vascular $(n=2)$, plastic $(n=2)$, burn $(n=1)$, trauma $(\mathrm{n}=1)$, and liver transplant $(\mathrm{n}=1)$ surgeries. The median age was 49 years, ranging from 31 to 67 years. Chronic opioid pain management was reported in 6 of 7 patients. Pain scores were assessed every two hours per protocol. Baseline median pain score was 8 using the adult nonverbal pain scale (ANVPS) (Table 1). Ketamine infusion rate was $0.06 \mathrm{mg} / \mathrm{kg} / \mathrm{hr}$ and lidocaine infusion rate was $0.5 \mathrm{mg} / \mathrm{min}$ upon initiation. The median time to a reduction in $20 \%$ pain scores from the start of both lidocaine and ketamine was two hours. At the median time of two hours of observing reduction of pain scores, the median ketamine infusion rate was at 0.5 $\mathrm{mg} / \mathrm{kg} / \mathrm{hr}$ and lidocaine was at $0.75 \mathrm{mg} / \mathrm{min}$. When opioid requirements were compared 24 hours prior and 24 hours of concurrent lidocaine and ketamine IV infusions, 4 out of 7 patients showed a decrease in the need for opioids (morphine dose equivalent $90.33 \mathrm{mg}$ vs. $56 \mathrm{mg}$ ). Lidocaine was weaned off prior to ketamine therapy in 4 of the 7 patients. The median duration of lidocaine and ketamine therapies was 32 hours and 52 hours, respectively. Table 2 contains patient demographics, average infusion rates, and outcomes.

Table 1. Adult NonVerbal Pain Scale (ANVPS) assessment.

\begin{tabular}{|c|c|c|c|c|}
\hline & 0 & 1 & 2 & Score \\
\hline Face & $\begin{array}{l}\text { No particular face } \\
\text { expression or smile }\end{array}$ & $\begin{array}{l}\text { Occasional grimace, } \\
\text { tearing, frown or } \\
\text { wrinkled forehead }\end{array}$ & $\begin{array}{l}\text { Frequent grimace, } \\
\text { tearing, frown, or } \\
\text { wrinkled forehead }\end{array}$ & \\
\hline Activity & $\begin{array}{l}\text { Lying quietly, } \\
\text { normal position }\end{array}$ & $\begin{array}{l}\text { Seeking attention } \\
\text { through movement of } \\
\text { slow cautious } \\
\text { movements }\end{array}$ & $\begin{array}{c}\text { Restless activity } \\
\text { and/or withdrawal } \\
\text { reflexes }\end{array}$ & \\
\hline Guarding & $\begin{array}{l}\text { Lying quietly, no } \\
\text { positioning of } \\
\text { hands over areas of } \\
\text { body }\end{array}$ & $\begin{array}{l}\text { Splinting areas of the } \\
\text { body }\end{array}$ & Rigid, stiff & \\
\hline Physiologic & $\begin{array}{c}\text { Stable vital signs, } \\
\text { no change in past } 4 \\
\text { hours }\end{array}$ & $\begin{array}{l}\text { Change over past } 4 \\
\text { hours in any of the } \\
\text { following } \\
S B P>20, H R>20, \\
R R>10\end{array}$ & $\begin{array}{c}\text { Change over past } 4 \\
\text { hours in any of the } \\
\text { following: } \\
\text { SBP }>30, H R>25, \\
\text { RR }>20\end{array}$ & \\
\hline Respiratory & $\begin{array}{l}\text { Baseline RR/Spo2 } \\
\text { Complaint with } \\
\text { ventilator }\end{array}$ & $\begin{array}{c}\text { RR }>10 \text { above baseline } \\
\text { or } 5 \% \text { decrease in } 5 \text { po } 2 \\
\text { Mild asynchrony with } \\
\text { ventilator }\end{array}$ & $\begin{array}{c}\mathrm{RR}>20 \text { above } \\
\text { baseline or } 10 \% \\
\text { decrease in } 5 \text { po } 2 \\
\text { Severe asynchrony } \\
\text { with ventilator }\end{array}$ & \\
\hline
\end{tabular}

Two significant adverse drug reactions were reported. Patient case 5 was a 63 -year-old male with a history of chronic alcohol abuse with infected thoracic spine wound. The patient developed altered mental status, tremors, and left-sided facial droop while receiving lidocaine infusion at $2 \mathrm{mg} / \mathrm{min}$ for 43 hours and ketamine at $4 \mathrm{mcg} / \mathrm{kg} / \mathrm{min}$ for 39.5 hours. A magnetic resonance imaging (MRI) of the brain was performed, which was negative for a stroke. Lidocaine level was elevated at $6 \mathrm{mcg} / \mathrm{ml}$. The improvement in mental status was noted 6 hours after the discontinuation of lidocaine and ketamine. The Naranjo Adverse Drug Reaction Probability Scale (NADRPS) classifies this as a probable ADR (score of 5) [8] .

Patient case 7 was a 67-year-old female with a history of fibromyalgia, carpal tunnel, and peripheral neuropathy admitted for a nerve block complication. The patient was receiving lidocaine patches prior to admission but was not continued while inpatient. The patient developed altered mental status, nausea/vomiting while receiving lidocaine at $0.5 \mathrm{mg} / \mathrm{min}$ for 11.5 hours and ketamine infusion at 10 $\mathrm{mcg} / \mathrm{kg} / \mathrm{min}$ for 10.5 hours. A lidocaine level was not drawn. The improvement was noted 5.5 hours after 
lidocaine and ketamine discontinuation. It cannot be determined if the altered mental status was contributed by lidocaine, ketamine, or both since the therapies were discontinued simultaneously. The NADRPS classifies this as a possible ADR (score of 4) [8] .

Table 2. This is the patient data for research.

\begin{tabular}{|c|c|c|c|c|c|c|c|c|c|}
\hline \multirow[t]{2}{*}{ Case } & \multirow[t]{2}{*}{$\begin{array}{l}\text { Age/ } \\
\text { Gender }\end{array}$} & \multirow{2}{*}{$\begin{array}{l}\text { Pain score } \\
\text { upon dual } \\
\text { therapy } \\
\text { initiation }\end{array}$} & \multirow{2}{*}{$\begin{array}{l}\text { Ketamine } \\
\text { average dose } \\
(\mathrm{mcg} / \mathrm{kg} / \mathrm{min})\end{array}$} & \multirow{2}{*}{$\begin{array}{l}\text { Ketamine } \\
\text { duration } \\
\text { (h) }\end{array}$} & \multirow{2}{*}{$\begin{array}{l}\text { Lidocaine } \\
\text { duration } \\
\text { (h) }\end{array}$} & \multirow{2}{*}{$\begin{array}{l}\text { Lidocaine } \\
\text { average } \\
\text { dose } \\
\left(\mathrm{mg} / \mathrm{min}^{\mathrm{e}}\right)\end{array}$} & \multirow{2}{*}{$\begin{array}{l}\text { Time to } \\
20 \% \text { pain } \\
\text { reduction } \\
\text { (h) }\end{array}$} & \multicolumn{2}{|c|}{$\begin{array}{l}\text { Morphine Equivalent } \\
\text { Requirement (mg) }\end{array}$} \\
\hline & & & & & & & & $\begin{array}{l}\text { Pre dual } \\
\text { therapy }\end{array}$ & $\begin{array}{l}\text { Post dual } \\
\text { therapy }\end{array}$ \\
\hline 1 & $43 / \mathrm{F}^{\mathrm{a}}$ & 7 & 6.4 & 52 & 31 & 0.25 & 1 & 90.33 & 36.67 \\
\hline 2 & $31 / \mathrm{M}^{\mathrm{a}}$ & 8 & 6.1 & 95.5 & 32 & 1.72 & 2 & 123 & 74.67 \\
\hline 3 & $58 / \mathrm{M}$ & 7 & 5.7 & 167 & 31 & 1.94 & 23 & 106.67 & 56 \\
\hline 4 & $51 / \mathrm{F}$ & 10 & 5.6 & 42 & 45 & 0.50 & 3 & 45 & 45 \\
\hline 5 & $63 / \mathrm{M}$ & 9 & 3.8 & 39.5 & 43 & 2.00 & 2 & 25 & 19.17 \\
\hline 6 & $45 / F$ & 8 & 8.0 & 138.5 & 57.5 & 0.91 & 3 & 90.33 & 171.3 \\
\hline 7 & $67 / F$ & 10 & 9.8 & 10.5 & 11.5 & 0.54 & 2 & 9.3 & 14.3 \\
\hline \multicolumn{2}{|c|}{ Median } & 8 & 6.1 & 52 & 32 & 0.91 & 2 & 90.33 & 56 \\
\hline
\end{tabular}

a $\mathrm{F}=$ female, $\mathrm{M}=$ male; $^{\mathrm{b}} \mathrm{h}=$ hours; $^{\mathrm{c}} \mathrm{kg}=$ kilograms; $^{\mathrm{d}} \mathrm{mg}=$ milligram; ${ }^{\mathrm{e}} \mathrm{min}=$ minutes.

\section{DISCUSSION}

Continuous lidocaine IV and ketamine IV infusion therapies have been separately evaluated for its effectiveness for the management of pain as adjunct therapies to opioid-based regimen. Both therapies have shown effectiveness in reducing opioid consumption especially in post-operative patients [3,7]. These findings are particularly important since the SCCM guidelines have recommended to reduce opioid use due to the adverse events particularly CNS and respiratory depression. The guidelines strongly suggest the use of multimodal approach through the use of other agents such as acetaminophen, ketamine, dexmedetomidine, nonsteroidal anti-inflammatory drugs (NSAID) and gabapentinoids [1] .

A study evaluating 21 ICU patients received IV lidocaine infusion for adjunct pain therapy statistically received less morphine dose equivalents at 6,12 , and 24 hours $(p=0.002, p=0.002$, and $p=0.037$, respectively). Neurological adverse events were noted in $14 \%$ of the patients [3]. A meta-analysis evaluated continuous IV infusion or single dose low dose ketamine for post-operative pain. The authors included 39 trials and showed a mean reduction of $40 \%$ of opioid consumption using low dose ketamine. No major complications were noted in the meta-analysis [7].

Of note, this is the first study evaluating the concurrent use of lidocaine and ketamine infusions as adjunct pain therapy in critically ill patients. This is a retrospective case series with a small sample size and no control groups are inherent limitations to the study. However, the results of the study helped develop lidocaine and ketamine infusion protocols for use at the study institution.

\section{CONCLUSION}

The results of this study suggest that low-dose lidocaine and ketamine infusions can be a safe and effective adjunctive treatment option for selected ICU patients with severe pain. However, future studies need to be conducted to determine the safety and effectiveness of concurrent use of lidocaine and ketamine infusions aside from surgical ICU patients.

\section{MATERIALS AND METHODS}

\subsection{Study design}

This was a retrospective case series of adult surgical ICU patients who received lidocaine and ketamine as adjunct to opioids from March 2014 to August 2015. The institutional review board approved this study (SPHS2015-003) for proper ethical and research standards. 


\subsection{Patient population}

The study included patients aged 18 years or older, ICU stay of at least 24 hours, and concurrent use of systemic lidocaine and ketamine infusions as adjunct therapies for pain management. The eligible patients were identified by querying the electronic medical record (EMR) data for any patients who received both therapies. The exclusion criteria includes insufficient data (i.e., pain score, medications administered), patient less than 18 years, and non-critically ill patient. A manual chart review was performed on each patient. Data collected includes patient demographics, average dose of lidocaine and ketamine, opioid medications received, adverse events that occurred during receipt of lidocaine and ketamine, and duration of the dual therapy.

\subsection{Outcomes}

The primary outcomes included the time measurement to achieve a $20 \%$ reduction in pain scores after the initiation of lidocaine and ketamine and the difference in opioid requirements pre and post concurrent pain therapies. Secondary outcomes include development of adverse events while on dual therapy. These outcomes were selected as previous studies have evaluated the same outcomes [3]. The primary author evaluated all the patients and their outcomes for consistency.

\subsection{Data analysis}

Data were summarized using descriptive statistics.

Acknowledgements: We would like to show our gratitude to Yoonsun Mo, PharmD, MS, BCPS, BCCCP from Long Island University for sharing her pearls of wisdom with us during the course of this research.

Author contributions: Concept - A.A., Design - A.A.; Supervision - A.A.; Materials - A.E.; Data Collection and/or Processing - A.A., A.E.; Analysis and/or Interpretation - A.A., A.E.; Literature Search - A.A., A.E., Writing - A.A., A.E., Critical Reviews - A.E., A.A.

Conflict of interest statement: There are no conflicts of interest. The authors did not receive grant support or research funding for this study.

\section{REFERENCES}

[1] Barr J, Fraser GL, Puntillo K, Ely EW, Gélinas C, Dasta JF, Davidson JE, Devlin JW, Kress JP, Joffe AM, Coursin DB, Herr DL, Tung A, Robinson BR, Fontaine DK, Ramsay MA, Riker RR, Sessler CN, Pun B, Skrobik Y, Jaeschke R. American College of Critical Care Medicine. Clinical practice guidelines for the management of pain, agitation, and delirium in adult patients in the intensive care unit. Crit Care Med. 2013; 41(1): 263-306. [CrossRef]

[2] Barr J, Pandharipande PP. The pain, agitation, and delirium care bundle: synergistic benefits of implementing the 2013 Pain, Agitation, and Delirium Guidelines in an integrated and interdisciplinary fashion. Crit Care Med. 2013; 41: 99-115. [CrossRef]

[3] Mo Y, Thomas MC, Antigua A, Ebied A, Karras GE Continuous lidocaine infusion as adjunctive analgesia in intensive care unit patients. J Clin Pharmacol. 2017; 57(7): 830-836. [CrossRef]

[4] Kranke P, Jokinen J, Pace NL, Schnabel A, Hollmanm MW, Hahnenkamp K, Eberhart LHJ, Poepping DM, Weibel S. Continuous intravenous lidocaine infusion for postoperative pain and recovery. Cochrane Database Syst Rev. 2015; 16(7): CD009642. [CrossRef]

[5] Herroeder S, Pecher S, Schönherr ME, Kaulitz G, Hahnenkamp K, Friess H, Böttiger BW, Bauer H, Dijkgraaf MG, Durieux ME, Hollmann MW. Systemic lidocaine shortens length of hospital stay after colorectal surgery: A double-blinded, randomized, placebo-controlled trial. Ann Surg. 2007; 246(2): 192-200. Erratum in: Ann Surg. 2009; 249(4): 701. [CrossRef]

[6] Chou R, Gordon DB, de Leon-Casasola OA, Rosenberg JM, Bickler S, Brennan T, Carter T, Cassidy CL, Chittenden EH, Degenhardt E, Griffith S, Manworren R, McCarberg B, Montgomery R, Murphy J, Perkal MF, Suresh S, Sluka K, Strassels S, Thirlby R, Viscusi E, Walco GA, Warner L, Weisman SJ, Wu CL. Management of postoperative pain: A clinical practice guideline from the American Pain Society, the American Society of Regional Anesthesia and Pain Medicine, and the American Society of Anesthesiologists' Committee on Regional Anesthesia, Executive Committee, and Administrative Council. J Pain. 2016; 17(2): 131-157. [CrossRef]

[7] Jouquelet-Lacoste J, La Colla L, Schilling D, Chelly JE. The use of intravenous or single dose of low-dose ketamine for postoperative analgesia: a review of the current literature. Pain Med. 2015; 16(2): 383-403. [CrossRef]

[8] Naranjo CA, Busto U, Sellers EM, Sandor P, Ruiz I, Roberts EA, Janecek E, Domecq C, Greenblatt DJ. A method for estimating the probability of adverse drug reactions. Clin Pharmacol Ther. 1981; 30(2): 239-245. 